\title{
HOMERO Y VIRGILIO EN SATURNALIA DE MACROBIO: UN AGÓN LITERARIO
}

\author{
Julieta Cardigni \\ UBA- CONICET \\ jcardigni@yahoo.es
}

Macrobio dedicó especialmente uno de sus textos, Saturnalia (s. V d. C.) a la discusión de la obra y la persona de Virgilio -considerado tanto autoridad poética como filosófica y religiosa- aplicando como estrategia la comparación con la otra gran auctoritas de la Antigüedad: Homero. Si bien el punto de partida es la valoración de las habilidades literarias, la competencia se dirime finalmente apelando al plano de la moral y del respeto por la tradición, ambos contemplados en la práctica de la imitatio, fundamental en la Antigüedad Tardía y en particular en la obra macrobiana.

Antigüedad Tardía / Saturnalia / agón literario / Homero / Virgilio

\section{HOMER AND VIRGIL IN MACROBIUS' SATURNALIA: A LITERARY AGÓN}

Macrobius dedicated his text Saturnalia (V A.D) to the discussion of Virgil's figure and literary works, building him as a paradigm of knowledge through the comparison with the other great magister of Antiquity: Homer. The purpose of the present paper is to analyze this macrobian operation in order to establish which of the two poets gets the first place in this friendly agón. Though the starting point seems to be the valuation of the literary skills of each contestant, the competence is solved appealing to the practice of imitatio, a main virtue in Late Antiquity and in Macrobius work.

Late Antiquity / Saturnalia / literary agon / Homer / Virgil 
Los valores sociales y morales del universo macrobiano: la figura de Virgilio

$\mathrm{E}$

n Saturnalia, escrita en el siglo V d. C. y que ha sido definida como un de officiiis tardoantiguo ${ }^{1}$, Macrobio busca transmitir de manera orgánica, coherente y completa todos los saberes de la Antigüedad grecolatina a la manera de un compendio dedicado a su hijo Eustacio ${ }^{2}$. Podemos imaginar las dificultades de tamaña empresa, no solo por el hecho de la cantidad de información que en principio debería ser consignada para cumplir con el imperativo macrobiano, sino también por la falta de contradicción a la que la obra aspira, y que resulta difícil mantener al abrevar de textos y saberes diferentes. Estos dos aspectos convierten a Macrobio en un gran compilador y conciliador de la tradición clásica, lo cual de alguna manera compensa las "traiciones" a las palabras de los auctores que podemos detectar en su obra - y sobre las que él mismo nos alerta en la Praefatio ${ }^{3}$ - producto de este afán totalizador y unificador. Por otro lado, este proyecto macrobiano se condice perfectamente con la estructura y ambiente de Saturnalia, obra que pone en escena una reunión de hombres ilustrados en la cual se discute, de manera ordenada y civilizada, acerca de grandes temas de la literatura latina, proponiéndose una suerte de círculo

1 Cf. R. KASTER (1980). Sobre el Tardoantiguo y sus transformaciones cf. entre otros BrowN (1971); CAMERON (1998).

2 Macrobio, Sat. Praef. 1-2: Multas variasque res in hac vita nobis, Eustatii fili, natura conciliavit: sed nulla nos magis quam eorum qui e nobis essent procreati caritate devinxit, eamque nostram in his educandis atque erudiendis curam esse voluit, ut parentes neque, si id quod cuperent ex sententia cederet, tantum ulla alia ex re voluptatis, neque, si contra eveniret, tantum maeroris capere possent. "La naturaleza, mi querido hijo Eustacio, nos ha brindado cosas en abundancia y muy variadas. Ahora bien, con nada nos ha atado más que con el amor a nuestros hijos; ha establecido que nuestra preocupación sea su educación y su formación, hasta el punto que un padre no puede obtener mayor satisfacción que ver cumplido su proyecto de acuerdo con sus deseos ni, en caso contrario, siente una mayor tristeza." El Eustacio hijo y dedicatario de Saturnalia y los Commentarii in Somnium Scipionis ha sido identificado como el prefecto de la ciudad del año 462, cf. Alan CAMERON (1966), (2011) y PANCIERA (1982).

3 Macrobio, Sat. Praef. 3: Nec indigeste tamquam in acervum congessimus digna memoratu: sed variarum rerum disparilitas, auctoribus diversa confusa temporibus, ita in quoddam digesta corpus est, ut quae indistincte atque promiscue ad subsidium memoriae annotaveramus in ordinem instar membrorum cohaerentia convenirent. "Tampoco he acumulado lo digno de memoria de modo indigesto, como en un montón; al contrario, la exposición de los diversos y diferentes asuntos, diversa en autores, en tiempos desordenada, ha sido digerida en una especie de cuerpo, de modo que lo que había observado de modo confuso y mezclado se pueda reunir, para ayudar a la memoria, en cierto orden gracias a la cohesión de sus miembros." 
social idealizado basado en la nostalgia por el pasado cultural ${ }^{4}$. Pero, por sobre todo, el objetivo del diálogo es establecer y transmitir una noción de armonía social que así como se ve reflejada en el comportamiento de los hombres en el banquete, se proyecta hacia el pasado y a la relación con los auctores que aparecen citados. Esta armonía supone también la conciliación, la continuidad y la amicitia con la romanitas tradicional, imperativos que rigen todo el desarrollo de la obra ${ }^{5}$. Así lo afirma el autor en su Praefatio (10), cuando explica sus objetivos a su hijo: Tale hoc praesens opus volo: multae in illo artes, multa praecepta sint, multarum aetatum exempla, sed in unum conspirata. ("Quiero que esta obra sea así: que haya en ella muchas técnicas, muchos preceptos, ejemplos de muchas épocas, pero completamente armonizados.")

Entre las estrategias con que cuenta Macrobio para llevar a cabo su tarea, la construcción de Virgilio como poeta y auctoritas resulta una de las principales. En primer lugar por su alcance simbólico, que garantizaba una comunicación fluida con el lector, ya que constituía el centro de la koiné literaria de todos los hombres educados. En segundo lugar, esta omnipresencia le concede a la figura virgiliana una flexibilidad y permeabilidad bajo la cual sus características se desdibujan y resurgen en formas diferentes, manteniendo como denominador común el supuesto de su prestigio y autoridad en la tradición poética. Estos rasgos convierten a Virgilio en una suerte de recipiente flexible y particularmente apto para rellenar y proponer como modelo de cultura y de saber. De alguna manera es, además del eje temático de Saturnalia, una buena metáfora de su propuesta. Por otra parte, si bien Macrobio le dedica explícitamente al poeta mantuano este diálogo, no lo omite en sus otras dos obras, De differentiis y los Commentarii in Somnium Scipionis, en las que es sucesivamente autoridad gramatical y filosófica, mostrando cómo desde diferentes disciplinas Virgilio es siempre un exemplum.

Virgilio es caracterizado en Saturnalia desde muy temprano (1.16.44) como poseedor de dos elementos que rigen — junto con la verecundiael universo socioliterario de Saturnalia: diligentia y doctrina ${ }^{6}$ : Item poeta doctrina ac uerecundia nobilis ("El mismo poeta noble por su erudición

4 Sobre la idealización del círculo de Pretextato, cf. De Paolis (1987).

5 Sobre la amicitia en Saturnalia, cf. KASTER (1980).

6 Cf. KASTER (1980). La diligentia, el escrúpulo al realizar una tarea, y la uerecundia, el respeto hacia los demás surgido de conocer el lugar apropiado en el que desempeñarse en sociedad, van para Macrobio unidas en un binomio del cual surge la doctrina. Es decir que el conocimiento se basa, en Saturnalia, en virtudes que no son únicamente intelectuales sino que van asociadas indisolublemente a prácticas morales. Desde esta perspectiva, una lectura apropiada y correcta de los auctores y la garantía de la continuidad cultural por medio de la imitatio no son simples acciones literarias sino imperativos socio-morales. 
y su respeto $\left.{ }^{7} . "\right)$ Esta fórmula coincide con la que Macrobio ha utilizado al comienzo del diálogo para describir al grammaticus Servio, quien será el modelo perfecto de uerecundia durante el simposio: Hos Seruius inter grammaticos doctorem recens professus, iuxta doctrina mirabilis et amabilis uerecundia, terram intuens et uelut latenti similis sequebatur. (Macr., Sat. 1.2.15: "Entre estos venía Servio, recientemente nombrado como docto entre los gramáticos, admirable por su doctrina y agradable por su uerecundia, con los ojos mirando el piso y como escabulléndose.") Asimismo, Virgilio es también en Saturnalia 5.18.15 paradigma de diligentia: In qua quidem re mirari est poetae huius occultissimam diligentiam. ("Ciertamente, en relación con este asunto es de admirar la agudísima precisión de este poeta.") Y también, en 5.18.18: Animaduertitis diligentissime uerba Euripidis a Marone seruato. ("¿Observan con qué diligencia las palabras de Eurípides fueron respetadas por Virgilio? Pues aquel dice: 'descalzos del pie izquierdo', y el mismo pie desnudo también lo mencionó Virgilio: 'marcan las huellas desnudas de su pie izquierdo'.) El poeta mantuano se transforma así en símbolo de esta sociedad literaria, utópica e ideal a la que Macrobio aspira y que Saturnalia describe.

Por otro lado, encontramos también en otro pasaje de la obra una presentación del poeta que lo proyecta más allá del universo literario. En 1.24.2-4, cuando Evángelo ataca la figura de Virgilio señala que:

Equidem, inquit, miror potuisse tantorum potestatem numinum conprehendi: uerum, quod Mantuanum nostrum ad singula, cum de diuinis sermo est, testem citatis, gratiosius est quam ut iudicio fieri putetur. An ego credam, quod ille, cum diceret: Liber et alma Ceres pro sole ac luna, non hoc in alterius poetae imitationem posuit, ita dici audiens, cur tamen diceretur ignorans? Nisi forte, ut Graeci omnia sua in inmensum tollunt, nos quoque etiam poetas nostros uolumus philosophari: cum ipse Tullius, qui non minus professus est philosophandi studium quam loquendi, quotiens aut de natura deorum aut de fato aut de diuinatione disputat, gloriam quam oratione conflauit incondita rerum relatione minuat.

Ciertamente me asombra que se haya podido abarcar el poder de tantas deidades; ahora bien, que nuestro mantuano, cuando se conversa sobre los asuntos divinos, sea citado en relación con cada una de ellas en calidad de testimonio más bien resulta gracioso que pueda considerarse justificado. ¿YYo debo creer que él, al decir 'Líber y la nutricia Ceres' en lugar del Sol y la Luna, no pudo decir esto para imitar a otro poeta, al oír que se decía así, ignorando, sin embargo, por qué se decía? Salvo que,

7 La cita virgiliana es de G. 1.5-7. 
por casualidad, al igual que los griegos dicen de todo lo suyo que es lo más grande, nosotros también queramos que nuestros poetas filosofen, cuando el propio Cicerón, que no se dedicó menos al estudio de la filosofía que al de la oratoria, cuantas veces disputa sobre la naturaleza de los dioses o del destino, o sobre la adivinación, disminuye su gloria —que resplandeció con la oratoria- al relacionar sin arte sus argumentos.

Desde esta perspectiva serían las lecturas de los romanos, deseosos por contar con grandes figuras literarias y filosóficas, las que han transformado a Virgilio en esa figura omnisciente, poeta, sabio y filósofo a la vez, a la que todos veneran. Al mismo tiempo el término "imitatio", que retomaremos en breve, parece disminuir el mérito virgiliano en este pasaje. Esta denuncia que resulta valiosa para nosotros — porque evidencia la actitud exegética hacia Virgilio - y para la economía narrativa de la obra - porque permite que se inicie la larga exposición sobre los valores virgilianos-genera una decidida desaprobación entre los asistentes al banquete, y queda así perfectamente claro por qué Evángelo ha pasado a ser en la tradición macrobiana un personaje de carácter negativo ${ }^{8}$. La respuesta de Símaco no se hace esperar (1.24.10), y a partir de su discurso queda fijado, de manera programática, el tema del diálogo y la línea en que seguirán las discusiones literarias:

Si in hac opinione es, inquit Symmachus, ut Maro tibi nihil nisi poeticum sensisse aestimetur, licet hoc quoque eidem nomen inuideris: audi, quid de operis sui multiplici doctrina ipse pronuntiet. Ipsius enim Maronis epistola, qua conpellat Augustum, ita incipit: 'Ego uero frequentes a te litteras accipio', et infra: 'De Aenea quidem meo, si mehercle iam dignum auribus haberem tuis, libenter mitterem: sed tanta inchoata res est, ut paene uitio mentis tantum opus ingressus mihi uidear, cum praesertim, ut scis, alia quoque studia ad id opus multoque potiora inpertiar.'

Si tienes la opinión, dijo Símaco, de que Virgilio no ha de considerarse nada más que un poeta, por más que no le has dado tampoco este nombre, escucha qué dice él sobre la erudición en su múltiple obra. Una

8 El hecho de que este personaje no se adapte a las normas de la uerecundia tan apreciadas en el banquete ha generado las más diversas opiniones entre los críticos. Entre ellas, aquella que lo hace representante de un cristianismo atacado silenciosamente por Macrobio, y que justificaría la inclusión de un personaje con ese nombre. Al respecto de la polémica cf. el estudio preliminar de la edición de Saturnalia de Kaster (2011). En nuestra opinión, no hay un ataque al cristianismo por un lado, y por otro, Evángelo actúa de esa manera porque funciona como antagonista y ayuda a hacer avanzar el diálogo y a delinear los personajes, es decir que su comportamiento responde a necesidades narrativas de la obra. 
carta del propio Virgilio, dirigida a Augusto, comienza así: 'En realidad, recibo con frecuencia cartas tuyas' y más abajo 'ciertamente sobre mi Eneas, si tuviera, por Hércules, algo digno de tus oídos, te lo enviaría libremente, pero es tan grande el asunto iniciado que apenas con un desvarío de la mente me parece que me he introducido en una obra tan grande, incluso cuando, como sabes, consagre mi esfuerzo a estudios mucho más elevados para esta obra.

A la propuesta de que Virgilio es "nada más que un poeta" Símaco contrapone de manera indirecta las propias palabras del mantuano, quien expresa la variedad de conocimientos y habilidades necesarios para la composición de sus obras. Con esta afirmación queda claro que la tendencia de todo el texto de Saturnalia es considerar a Virgilio como mucho más que un exponente literario: será filósofo, orador y sabio.

Asimismo Macrobio encuadra la opinión de Evángelo en su propia crítica a la escuela del gramático (1.24.12) que, incapaz de ver detrás de las palabras, sólo lee los textos en la superficie y no indaga sobre su verdadero significado:

Nec his Virgilii uerbis copia rerum dissonat, quam plerique omnes litteratores pedibus inlotis praetereunt, tamquam nihil ultra uerborum explanationem liceat nosse grammatico. Ita sibi belli isti homines certos scientiae fines et uelut quaedam pomeria et effata posuerunt, ultra quae si quis egredi audeat, introspexisse in aedem deae a qua mares absterrentur existimandus sit.

Y no es discordante con estas palabras de Virgilio la abundancia de asuntos que la mayoría de todos los gramáticos pasan de largo con los pies sucios, como si no le fuera lícito al gramático conocer en absoluto una explicación más allá de las palabras. Así, esos hombres exquisitos impusieron unos rígidos límites seguros a su ciencia a modo de espacios sagrados consagrados; si alguien osara avanzar más allá de estos, debía considerarse que había penetrado en el templo de la diosa de la que los hombres se alejan con horror.

La figura del mal gramático queda claramente delineada con la imagen "pedibus inlotis", que además de significar que una cuestión se realiza con ligereza, superficialidad o falta de preparación —lo opuesto a la diligentia - también posee una connotación religiosa, por el origen de la frase, relacionado con las abluciones necesarias antes de la realización de los sacrificios. En contraste Macrobio, por boca de Símaco, se opone a esta opinión que manifiesta Evángelo - y que los grammatici actualizan en 
sus lecturas, anulando la vasta sabiduría de Virgilio- y propone en cambio asumir la tarea de leer al poeta en toda su dimensión, sin dejar de lado la variedad temática y la profundidad de sus reflexiones solo por el hecho de que esto represente un desafío9: Sed nos, quos crassa Minerva dedecet, non patiamur abstrusa esse adyta sacri poematis, sed archanorum sensuum inuestigato aditu doctorum cultu celebranda praebeamus reclusa penetralia. (1.24.10: "Mas a nosotros, a quien una tosca Minerva no nos desagrada, no debemos soportar que se hayan escondido los santuarios del poeta sagrado sino que, investigando el acceso a los conocimientos arcanos, facilitemos que las puertas secretas sean celebradas por el culto de los sabios."). Virgilio funciona, así, como punto de partida para todas las reflexiones y como modelo para la práctica exegética, dado que extiende sus propios valores compositivos a las operaciones de lectura hechas sobre su obra. Así, reconocer la amplitud temática en las obras de Virgilio es al mismo tiempo erguirse como exégetas a la altura de su sabiduría.

En consonancia con este principio de omnisciencia virgiliana, es muy frecuente en Saturnalia la proyección de la figura del mantuano a otros ámbitos del saber, partiendo siempre de observaciones literarias sobre sus poemas (Eneida en particular). Entre estas se encuentran, por ejemplo, varias muy interesantes acerca de las fuentes que utilizó Virgilio para la elaboración de algunos episodios narrativos de Eneida, punto en el cual Macrobio difiere de otros gramáticos como Cornuto, al que en general sigue, para proponer como fuente la tragedia griega, sobre todo la de Eurípides ${ }^{10}$. Es también notable la extensa descripción de las fuentes de Virgilio, griegas y latinas, y la confrontación verso a verso con Homero que desarrolla el personaje del rétor Eusebio en el libro quinto en que Virgilio se yergue como sabio en los cuatro estilos de la elocuencia, a diferencia de lo que ocurre con Cicerón ${ }^{11}$. El libro quinto (5.1.1) se abre con una nueva alabanza de Virgilio, considerado orador diligente además de poeta:

9 Recordemos que Calcidio (In Tim. 1) señalaba estas mismas dificultades en relación con la lectura de Platón, que son casi un tópico en los comentarios y otros géneros afines: Timaeus Platonis et a ueteribus difficilis habitus est atque existimatus ad intellegendum non ex inbecillitate sermonis obscuritate nata, -quid enim illo uiro promptius?- sed quia legentes artificiosae rationis, quae operatur in explicandis rerum quaestionibus, usum non habebant stili genere sic instituto, ut non alienigenis sed propriis quaestionum probationibus id quod in tractatum uenerat ostenderetur.

10 Cf. la discusión acerca del episodio de Dido, en Sat. 5.19.1. Macrobio realiza allí un verdadero rastreo de 'intertextos' comparando las palabras de Virgilio y de los trágicos griegos.

11 Estos cuatro estilos son definidos un poco más adelante, en 5.1.7 por Eusebio: Quattuor sunt, inquit Eusebius, genera dicendi: copiosum, in quo Cicero dominatur: breue, in quo Salustius regnat: siccum, quod Frontoni ascribitur: pingue et floridum in quo Plinius 
Post haec cum paulisper Eusebius quieuisset, omnes inter se consono murmure Virgilium non minus oratorem quam poetam habendum pronuntiabant, in quo et tanta orandi disciplina et tam diligens obseruatio rhetoricae artis ostenderetur.

Después, al haberse tomado Eusebio un momento de respiro, todos en un armonioso murmullo comentaban entre sí que Virgilio no debía considerarse menos orador que poeta, en el cual no sólo se mostraba un gran conocimiento de la oratoria sino una diligente observancia del arte retórica.

A continuación, y como Avieno planteara la cuestión acerca de si Cicerón es superior a Virgilio en el arte oratoria, Eusebio responde (5.1.3-5):

Video quid agas, inquit Eusebius, quid intendas, quo me trahere coneris: eo scilicet, quo minime uolo, ad conparationem Maronis et Tullii. Verecunde enim interrogasti, uter eorum praestantior, quandoquidem necessario is plurimum conlaturus sit qui ipse plurimum praestat. Sed istam mihi necessitatem altam et profundam remittas uolo: quia non nostrum inter illos tantas conponere lites, nec ausim in utramuis partem talis sententiae auctor videri. Hoc solum audebo dixisse, quia facundia Mantuani multiplex et multiformis est et dicendi genus omne conplectitur. Ecce enim in Cicerone uestro unus eloquentiae tenor est, ille abundans et torrens et copiosus. Oratorum autem non simplex nec una natura est: sed hic fluit et redundat, contra ille breuiter et circumcise dicere adfectat: tenuis quidam et siccus et sobrius amat quandam dicendi frugalitatem,

Secundus quondam et nunc nullo ueterum minor noster Symmachus luxuriatur. Sed apud unum Maronem haec quattuor genera repperies. "Contesta Eusebio: 'Son cuatro los estilos oratorios: copioso el que domina Cicerón; breve en el que reina Salustio; seco que se adscribe a Frontón; denso y florido en el que antaño se consideraba a Plinio Segundo y ahora a nuestro querido Símaco, no inferior a cualquiera de los antiguos. Pero sólo en la obra de Virgilio encontrarás estos cuatro tipos.' " Macrobio, siguiendo probablemente una fuente tardía, añade un nuevo estilo oratorio, el "seco", para diferenciar los estilos de Salustio y Frontón, contra la doctrina antigua que distinguía únicamente tres estilos, tal como ha expuesto el mismo Macrobio en 5.5: Oratorum autem non simplex nec una natura est: sed hic fluit et redundat, contra ille breuiter et circumcise dicere adfectat: tenuis quidam et siccus et sobrius amat quandam dicendi frugalitatem, aliud pingui et luculenta et florida oratione lascivit. In qua tanta omnium dissimilitudine unus omnino Virgilius invenitur qui eloquentiam ex omni genere conflauerit. "La naturaleza de los oradores no es simple ni única, sino que fluye y redunda; uno aparenta hablar breve y conciso; otro suave, seco y sobrio ama una cierta frugalidad en la dicción; el otro es abigarrado con un discurso denso, rico y florido. En tan gran desemejanza de todo, evidentemente sólo se encuentra a Virgilio como quien ha utilizado cada uno de los estilos."

ARGOS 38 (2015) ISSN 0325-4194, pp. 72-90 
aliud pingui et luculenta et florida oratione lasciuit. In qua tanta omnium dissimilitudine unus omnino Virgilius inuenitur qui eloquentiam ex omni genere conflauerit.

Me doy cuenta de lo que haces, contestó Eusebio, de lo que te propones, hacia dónde tratas de arrastrarme, evidentemente por donde no quiero en absoluto: a la comparación entre Virgilio y Cicerón. Discretamente me has preguntado cuál de los dos es mejor, porque por fuerza aprovechará más el que más se destaque. Ahora bien, quiero que me liberes de esa alta y profunda dificultad, puesto que 'no me atrevería a disponer de tan gran certamen entre aquellos de los nuestros', ni a parecer el autor de una sentencia a favor de una u otra parte. Únicamente me atreveré a decir que la elocuencia del mantuano es múltiple y multiforme, y abarca todo tipo de estilo. He aquí pues que en su Cicerón hay un solo tenor de elocuencia: abundante, fluido y copioso. La naturaleza de los oradores no es simple ni única, sino que fluye y redunda; a saber, uno aparenta hablar breve y conciso; otro suave, seco y sobrio ama una cierta frugalidad en la dicción; el otro es abigarrado con un discurso denso, rico y florido. Esta gran desemejanza de todo, evidentemente sólo se encuentra a Virgilio como quien ha utilizado cada uno de los estilos. ${ }^{12}$

De acuerdo con su discurso, las ventajas de Virgilio por sobre Cicerón son la variedad, la amplitud y la versatilidad, puesto que maneja los cuatro estilos de la elocuencia frente a Cicerón que sólo maneja uno, aunque lo haga de manera indiscutiblemente diestra. Nos encontramos así con la idea de un autor y de una obra en los que confluyen todas las posibilidades, y eso los ubica por sobre los demás. Asimismo, y dado que las referencias de Virgilio sirven para enlazar la conversación con otros textos y autores de la tradición, no únicamente con Homero, la Eneida contiene a su vez toda la literatura, puesto que a partir de ella se pasa revista al canon completo. Aun más, el texto virgiliano trasciende el plano literario y contiene todo el saber: Macrobio inaugura así la tradición medieval de abrir la Eneida en cualquiera de sus páginas y extraer una máxima aplicable al asunto que se está conversando, lo cual transforma al poema virgiliano en una suerte de libro mágico de sabiduría ${ }^{13}$ o, como lo denomina parte de la crítica macrobiana, en una "Biblia pagana"14.

12 Las comillas encierran una cita de Ecl. 3.108, lo cual parece reforzar la decisión a favor de Virgilio.

13 Cf. Mesa Sanz (2009).

14 Cf. KASTER (1980); BLOCH (1963). 


\section{El agón literario entre Homero y Virgilio}

En el marco de esta presentación del poeta mantuano queda asimismo planteado el tema del agón, en tanto si Virgilio es erigido como la máxima autoridad literaria y religioso-filosófica, es cuestión de tiempo hasta que surjan las comparaciones, que se habían vislumbrado en el ya citado discurso de Eusebio referido a Cicerón. En ese sentido, el universo de Saturnalia se presenta en general como no competitivo, y los únicos disensos se plantean en función de hacer avanzar el discurso, casi como estrategias narrativas; incluso Eusebio se muestra reticente a elegir nostrum inter illos, y aunque finalmente lo hace, es de manera indirecta.

Sin embargo, con este antecedente no se hace esperar la comparación con el gran referente literario de toda la Antigüedad grecolatina: Homero. Por supuesto el tópico de la comparación entre Homero y Virgilio cuenta con una larga historia en el momento en que Macrobio escribe su obra. Ya Donato (s. IV d. C.) en su Vita Vergilii (195) consignaba y resumía las voces detractoras y apologéticas acerca del tema, atribuyéndolas a la Vita de Suetonio (46):

Asconius Pedianus libro, quem "Contra obtrectatores Vergilii" scripsit, pauca admodum obiecta ei proponit eaque circa historiam fere et quod pleraque ab Homero sumpsisset; sed hoc ipsum crimen sic defendere adsuetum ait: cur non illi quoque eadem furta temptarent? Verum intellecturos facilius esse Herculi clavam quam Homero versum subripere. Et tamen destinasse secedere ut omnia ad satietatem malevolorum decideret.

Asconio Pediano, en el libro que escribió "Contra los detractores de Virgilio", expuso muy pocas de las acusaciones hechas a él, y ésas casi siempre relacionadas con la historia y con el hecho de que había tomado de Homero una gran parte de cosas. Pero dice que solía defenderse de esta misma acusación así: ‘¿Por qué ellos no intentan también esos mismos plagios? Ciertamente comprenderán que es más fácil robar la maza de Hércules que un verso de Homero'. Y dice que, sin embargo, Virgilio decidió retirarse, para arreglar todo a satisfacción de los malvados.

Sin duda el tópico estaba instalado en la época de Macrobio, que tendría claro conocimiento de esta tradición ${ }^{15}$. En el caso de Donato (y de Suetonio) se manifiesta una fuerte tendencia a defender al poeta romano, tal como lo prueban la última frase, que califica de "malevoli" a sus

$\overline{15}$ Sobre la relación posible entre Macrobio y Donato, cf. MARINONE (1946). 
detractores, y la propia refutación virgiliana, que casi funciona como una conclusión del tema. El propio Servio presenta la relación entre Virgilio y Homero desde una perspectiva completamente diferente, como lo prueba el uso de "imitari" al inicio de sus Commentarii in Aeneidam, en oposición al "furta" que nos transmite Suetonio: intentio Vergilii haec est, Homerum imitari et Augustum laudare. ("La intención de Virgilio es esta: imitar a Homero y alabar a Augusto").

Saturnalia parece hacerse eco de esta última idea de "imitatio", cargada de significado positivo, ya que gran parte del diálogo es la discusión de la relación entre Virgilio y Homero. Evidentemente nuestro autor considera que es un debate que debe retomarse, pero desde esta posición de conciliación y de "amicitia" entre dos grandes poetas. En este contexto, la Eneida es considerada un reflejo especular de la Ilíada y de la Odisea:

Quid, quod et omne opus Virgilianum uelut de quodam Homerici opus speculo formatum est? Nam et tempestas mira imitatione descripta est (uersus utriusque qui uolet conferat), ut Venus in Nausicaae locum Alcinoi filiae succesit, ipsa autem Dido refert speciem regis Alcinoi conuiuium celebrantis.

¿Por qué ocurre que toda la obra virgiliana se formó como a partir de una cierta imagen de la obra homérica? Pues también la tempestad fue descrita gracias a una admirable imitación —compare ambas composiciones el que quiera- de manera que Venus apareció en lugar de Nausica, la hija de Alcinoo, y la propia Dido recuerda la imagen del rey Alcinoo al celebrar el banquete.

La comparación se presenta siempre de manera muy civilizada y atenuada, intentando eliminar todo espíritu de competencia y rivalidad, y constantemente haciendo hincapié en el hecho de que la obra virgiliana deriva de la homérica, y en este sentido se trata casi de un reconocimiento del parentesco que las liga y sobre el cual, en última instancia, se basa gran parte del prestigio de la Eneida. El cotejo macrobiano se extiende por varios parágrafos y consta básicamente de tres secciones: en 5.11 Virgilio supera a Homero; en 5.12 Virgilio se equipara a Homero; y en 5.13 Virgilio es inferior a Homero. En todos los casos Eusebio, armado con un volumen virgiliano que va repasando a medida que expone, señala pasajes en los que el mantuano ha tomado elementos homéricos, consigna las transformaciones que operó sobre él, y luego califica estas intervenciones como mejores, iguales o inferiores a las palabras de Homero. Virgilio supera a Homero, por ejemplo, en su transformación del pasaje de las abejas (Ilíada 2.87-93- Aen. 1.430-436): 
Et haec quidem iudicio legentium relinquenda sunt, ut ipsi aestiment quid debeant de utriusque collatione sentire. Si tamen me consulas, non negabo nonnumquam Virgilium in transferendo densius excoluisse, ut in hoc loco: Qualis apes aestate noua per florea rura

Exercet sub sole labor, cum gentis adultos

Educunt fetos, aut cum liquentia mella

Stipant et dulci distendunt nectare cellas,

Aut onera accipiunt uenientum aut agmine facto

Ignauum, fucos, pecus a praesepibus arcent.

Feruet opus, redolentque thymo fragrantia mella.

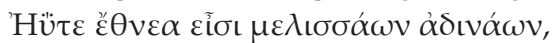

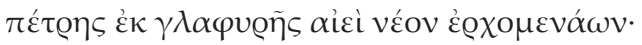

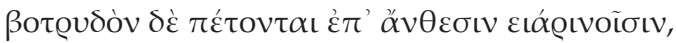

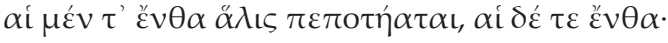

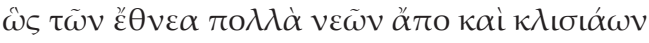

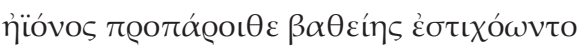

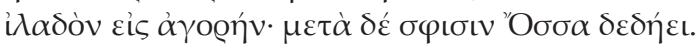

Vides descriptas apes a Virgilio opifices, ab Homero uagas: alter discursum et solam uolatus uarietatem, alter exprimit natiuae artis officium.

Debe dejarse sin duda a juicio de los lectores que ellos mismos consideren qué debe concluirse de la comparación de ambos autores. Sin embargo si me preguntas no negaré que en alguna ocasión Virgilio, al trasladar el modelo, consiguió una versión más elaborada, por ejemplo en el siguiente pasaje: 'Como una abeja al comienzo del verano por las flores silvestres/ realiza su trabajo bajo el Sol, cuando sacan los capullos/ adultos de su linaje, o cuando espesan la líquida/ miel e hinchan las dulces celdas con su néctar/ o reciben las cargas de las que vienen, o tras formar una columna/apartan de las colmenas al tropel indolente, los zánganos/ hierve el trabajo y las mieles fragantes exhalan olor a tomillo.' [y Homero] 'Como salen los enjambres copiosos de abejas/ y siempre nuevas se reúnen desde la hendidura de una peña/ y vuelan arracimadas sobre las flores primaverales/ unas, de este lado, zumban en grupo, otras de aquel/ así la multitud desde las naves y las tiendas cerca de la ribera profunda marchaba en fila/ hacia el ágora, entre ellos brillaba la Fama.' Ves que las abejas han sido descritas por Virgilio como trabajadoras, por Homero como inconstantes: uno desarrolla su recorrido y únicamente la variedad de su vuelo, otro el oficio de su arte natural.

Virgilio es un mejor observador de la naturaleza y además elige tomar aquellos rasgos de las abejas que constituyen elementos positivos e imitables: en este caso, la laboriosidad. Homero, en contraste, decide describir- 
las a partir de otras actitudes que Macrobio califica de vagas, "errantes", frente al opifices virgiliano. Vemos que si bien la comparación parte de los textos, el criterio para juzgar excede lo específicamente literario y suma un elemento moral que se aplica en la lectura, relacionado con la posibilidad de cada obra de erigirse como modelo ejemplar.

En otras ocasiones (5.12.1), Macrobio señala una equivalencia literaria entre ambos autores, que generalmente tiene que ver con el despliegue retórico- estilístico:

In aliquibus par paene splendor amborum est, uti:

- Spargit rara ungula rores

Sanguineos, mixtaque cruor calcatur arena.

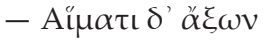

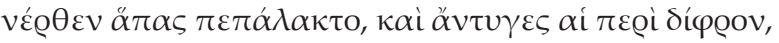

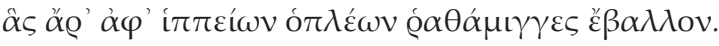

En algunos pasajes el esplendor de ambos autores es prácticamente igual, como en los siguientes: 'esparce con sus cascos rocíos/ sangrientos y pisotea la sangre mezclada con arena' (Aen.12.339-349), 'de sangre el eje/ por debajo estaba cubierto y las barandillas del carro (Il. 11.534-535).

Y en otros casos Virgilio es decididamente inferior (5.13.13), y la comparación se basa igualmente en cuestiones de estilo:

Et quia non est erubescendum Virgilio si minorem se Homero uel ipse fateatur, dicam in quibus mihi uisus sit gracilior auctore.

Tunc caput orantis nequicquam et multa parantis

Dicere deturbat terrae, truncumque reliquit.

Hi duo uersus de illo translati sunt:

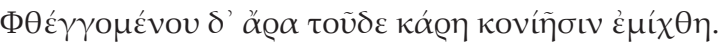

Vide nimiam celeritatem saluo pondere: ad quam non potuit conatus

Maronis accedere.

Y puesto que no ha de avergonzarse Virgilio, si afirma incluso él mismo que es inferior a Homero, diré en qué pasajes me pareció más simple que el original. 'Entonces la cabeza de quien rogaba en vano y trataba de decir/muchas cosas tira a tierra y abandona el tronco' (Aen. 10.554555). Estos dos versos fueron traducidos de los siguientes: 'Y la cabeza 
cayó en el polvo, mientras hablaba todavía.' Observa la extraordinaria rapidez con toda eficacia que no pudo alcanzar el intento de Virgilio. ${ }^{16}$

Como señalamos previamente, la divergencia está planteada a partir de la transformación que Virgilio hace a partir de Homero, que en algunos casos, como el que citamos, es "gracilior". No se trata estrictamente de una competencia, que atentaría contra el espíritu armonioso que propone Saturnalia, sino de una comparación amable entre dos grandes figuras que miden sus habilidades literarias. No obstante, y a pesar de la negativa de los personajes del diálogo a transformar la conversación en un agón, y si bien no hay un ganador explícito entre Homero y Virgilio, sí es posible deducir que la balanza se inclina hacia este último de manera indirecta, como ocurría en el caso en que se comparaba a Virgilio con Cicerón. Para no contrastar con el clima de amicitia y concordia que rige en este banquete filosófico, Macrobio encuentra una solución que no sólo no perturba el orden sino que, por el contrario, lo confirma.

\section{El culto de la imitatio}

La clave para dirimir la competencia amigable entre Homero y Virgilio está en recuperar otro de los valores fundamentales del diálogo -y del proyecto macrobiano en general- que contribuye a la continuidad y amicitia con la tradición: la imitatio. Se trata de un recurso literario que si bien cuenta con siglos de uso y aceptación, cobra en la Antigüedad Tardía una relevancia particular, al ser en esta época una de las formas más respetables — junto con la aemulatio y diferentes formas de comentarios ${ }^{17}$ de inscribir una obra en un universo literario que contaba ya con grandes auctores y textos reverenciados. En este sentido, Virgilio es insuperable, como el mismo Macrobio nos lo indica poco después en el mismo libro quinto (5.14.1-2), proyectando esta característica de su época al poeta:

Adeo autem Virgilio Homeri dulcis imitatio est, ut et in uersibus vitia quae a nonnullis inperite reprehenduntur imitatus sit, eos dico quos Graeci uocant

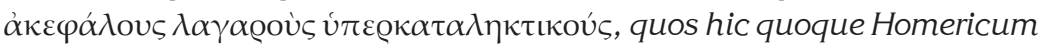

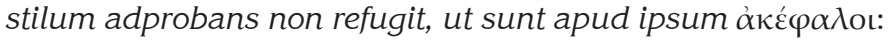

16 Señala MESA SAnz (2009: 393, n. 1122) que en la cita de Virgilio Macrobio reproduce "truncumque reliquit" en lugar del virgiliano "truncumque tegentem", probablemente se ha producido una contaminación con Aen. 12.382, abstulit esse caput truncumque reliquia harenae.

17 Cf. SLUITER (1998). 


\title{
Arietat in portas, - \\ Parietibus textum caecis iter, et similia,
}

\begin{abstract}
Hasta tal punto hay en Virgilio una complaciente imitación de Homero que en sus versos imitó incluso los defectos que con poco talento son censurados por algunos; me refiero a aquellos versos que los griegos denominan acéfalos, débiles e hipercatalécticos, que este no rehuyó, aceptándolos al adoptar un estilo heroico. Por ello, en su obra hay versos acéfalos: "embiste (arietai) contra las puertas (Aen. 11.890)... con paredes (parietibus) ciegas el pasadizo tejido (Aen. 5.589)....
\end{abstract}

Sigue a esta afirmación una descripción de los versos débiles y de los hipercatalécticos, que Virgilio también imita, así como "amables repeticiones de las que no huye" (Sunt amoenae repeticiones quas non fugit, Sat. 5.14.6) y numerosas otras estructuras, como por ejemplo ciertos versos más propios del habla común que de la poesía: Sunt apud Homerum uersus uulcis ac rasis similes et nihil differentes ab usu loquendi. Hos quoque tamquam heroice incomptos adamauit. (5.14.5: "Hay en la obra de Homero versos como depilados y rasurados, y nada diferentes al habla común. También [Virgilio] amó estos como si hubieran tenido sencillez heroica.") De la misma manera procede Virgilio con los epítetos homéricos, que "calca" en latín para no separarse de su modelo: Homerica quoque epitheta quantum sit ammiratus imitando confessus est. (Sat. 5.14.7: "Incluso confesó cuánto admiró los epítetos homéricos imitándolos")

Ya en el ámbito de lo narrativo, Virgilio incorpora, como Homero, numerosos eventos posteriores o anteriores a su narrativa de modo de evitar el estilo histórico cronológico, y al mismo tiempo mantenernos informados de acontecimientos importantes que hacen al relato. En este punto aparece también la aemulatio como parte del proceso, y como recordatorio de que, si bien de carácter pacífico, existe una cierta rivalidad literaria entre ambos autores (5.14.5-11):

Item diuinus ille uates res uel paulo uel multo ante transactas oportune ad narrationis suae seriem reuocat, ut et historicum stilum uitet non per ordinem digerendo quae gesta sunt, nec tamen praeteritorum nobis notitiam subtrahat. (...)Vergilius omne hoc genus pulcherrime aemulatus est.

Asimismo aquel divino vate [Homero] incorpora adecuadamente asuntos acaecidos mucho o poco antes en su relato, de manera que evita el estilo histórico, al no exponer por orden cronológico las hazañas realizadas 
$\mathrm{y}$, sin embargo, sin privarnos del conocimiento de los acontecimientos antiguos. (...) Virgilio emuló todo esto con gran brillantez.

Virgilio, fiel a uno de los valores que Macrobio y los hombres tardoantiguos más aprecian, imita de Homero hasta los considerados "errores", transformando la imitatio en un culto y en el canal de comunicación con la tradición cultural, y privilegiando así el diálogo con los auctores del pasado. Asimismo es lo mismo que Cicerón hace en su República con respecto a su modelo, Platón, y es la razón profunda por la cual Macrobio se esfuerza en conciliarlos siempre; también en el inicio de los Commentarii (1.1.2) nos advierte sobre esta cuestión: in hoc tamen uel maxime operis similitudinem seruauit imitatio ${ }^{18}$. Este principio es también el que guía la propia escritura macrobiana, ya que además de ser un valor que rige las relaciones sociales, es un imperativo moral que debe respetarse al abordar la composición literaria. Es por eso que Macrobio escribe un diálogo filosófico, y aunque introduce previsibles modificaciones al hacerlo ${ }^{19}$, su obra sigue siendo una imitación del banquete platónico, mediada por los nuevos valores literarios y morales que rigen la vida tardoantigua.

\section{Conclusiones}

En el universo literario de Macrobio la imitatio no es un recurso únicamente, sino una estrategia moral para cumplir con la deuda que se tiene hacia la tradición y hacia la propia cultura, una suerte de extensión de la amicitia que existe entre pares sociales, y que en ese caso, al aplicarse de manera diacrónica, homologa a los hombres del banquete con los grandes hombres de la tradición cultural. La figura de Virgilio emerge finalmente del diálogo como el perfecto balance entre tradición y presente en todas sus formas, ya que la obra poética del mantuano ha podido incorporar el pasado de manera uerecunda y construir así un saber apropiado e integrado. El papel de Virgilio en el proceso de continuidad cultural es análogo al de los individuos asistentes al simposio, se convierte en el paradigma por el que se rige toda la obra, y se extiende incluso a la tarea de Macrobio, que parece verse a sí mismo como un "continuador cultural". Virgilio es también un uno en el que confluyen múltiples y variadas tradiciones culturales, y funciona como símbolo de la propia búsqueda didáctico-literaria de

18 El propio Macrobio, como otros comentaristas tardíos, se transforma en un "imitador" de Cicerón al comentar el Somnium Scipionis, en tanto toma su vocabulario y su estilo para pegarse lo más posible a su texto fuente y crear la ilusión de un desprendimiento "natural" de sus palabras a partir del texto ciceroniano.

19 Cf. Flamant (1968). 
Macrobio: Nos quoque quicquid diversa lectione quaesivimus committemus stilo, ut in ordinem eodem digerente coalescat. (Praef. 6: "Todo lo que he encontrado en mis variadas lecturas lo reuniré igualmente con mi pluma, de tal manera que se una en orden con lo mismo que lo ordena."). ${ }^{20}$ Por supuesto, no podemos obviar el hecho de que la búsqueda de la unidad en la multiplicidad es una constante de la Antigüedad Tardía en todos los ámbitos, y la ecuación de cómo transformar lo múltiple en uno (y a la inversa) era un punto esencial en el pensamiento filosófico de la época ${ }^{21}$.

Finalmente, permítasenos una última reflexión, que también destaca el espíritu de Saturnalia y, aun más, el de las producciones culturales tardoantiguas. El agón entre Homero y Virgilio, de acuerdo con el espíritu de armonía que gobierna el diálogo, se encuentra estilizado por medio de la literatura ${ }^{22}$. Es, en apariencia, puramente literario, ya que a través de la imitatio se atenúa toda rivalidad; el homenaje literario conforma el velo a través del cual la competencia puede formar parte del diálogo pacífico de Saturnalia. No hay ganadores; Homero fue el primero, pero Virgilio lo imita, y de esta manera se mantiene la armonía de este universo utópico que se alza como una construcción posible de hombre, de saber y de mundo en el conflictivo siglo $\mathrm{V}$ d. C.

Macrobio ya vio en Virgilio lo que los pensadores medievales exaltarían en él durante los siglos posteriores ${ }^{23}$ : en la pluma de nuestro autor el mantuano es ya no sólo poeta, sino vate y sabio inspirado en todas las disciplinas. Virgilio era ya por supuesto el gran poeta latino y la autoridad pedagógica y literaria a la cual se remitían los hombres educados desde épocas muy anteriores a la de nuestro autor. Sobre esta base, Macrobio retoma su figura y la transforma en un modelo que trasciende estos campos específicos a través de su práctica de la imitatio, valor cultural fundamental del Tardoantiguo. El resultado es la imagen de Virgilio como el representante de una época que ya es evidentemente otra, como un paradigma cultural a seguir en tiempos azarosos, como el sabio que verá en él la Edad Media, como el guía omnisciente al que recurrirá Dante.

20 Esta idea está reforzada en la Praefatio por medio de una serie de metáforas que apuntan a la unión de la multiplicidad en la unidad: las abejas que liban las flores y obtienen la miel; los alimentos diferentes que consumimos y que nos dan fuerza; los perfumes que transmiten una fragancia a partir de múltiples elementos; y el coro cuyo sonido se eleva, único, formado por múltiples y variadas voces (Praef. 5-9).

21 Al respecto cf. COULTER (1976).

22 Como muchos otros elementos relacionados con las pasiones y los apetitos del cuerpo: la comida, la risa, el sexo; cf. Flamant (1968)

23 Coincidimos en esta apreciación con CuRTIus (1998). 


\section{Bibliografía}

\section{Fuentes}

Kaster, R. (2011) Macrobius. Saturnalia. Books 1-2, Harvard.

Mesa Sanz, J. F. (2009) Macrobio. Saturnales, Madrid.

Thilo, G. y Hagen, H. (eds.) (1881- 1902) Servius. Vergilii carmina commentarii, Leipzig.

Waszink J. H.- Jensen, P. J., (1962) Timaeus a Calcidio traslatus commentarioque instructus, "Plato Latinus", IV, Leiden.

WiLlis, I. (1970) Ambrosii Theodosii Macrobii Saturnalia apparatu critico instruxit, In Somnium Scipionis comentarios selecta varietate lectiois ornavit, I. Willis, vol. 2 Ambrosii Theodosii Macrobii Commentarii in Somnium Scipionis, edidit lacobus Willis, accedunt quatuor tabulae, Leipzig (reimpr. 1994).

\section{Bibliografía citada}

Bloch, H. (1963) "The pagan revival in the West at the end of the fourth century", en Momigliano, A. (ed.) The Conflict between Paganism and Christianity in the Fourth Century, Oxford, pp. 193-218.

Brown, P. (1971) The World of Late Antiquity: from Marcus Aurelius to Muhammad (A. D. 150- 750), London.

Cameron, Alan (1966) "The Date and Identity of Macrobius", JRS 56, pp. 25-38.

- (2011) The Last Pagans of Rome, Oxford.

Cameron, Averil (1998) El mundo mediterráneo en la Antigüedad Tardía, (395- 600), Crítica, Barcelona (1 $\stackrel{a}{\text { a }}$ edición Routledge, London, 1993).

Coulter, J. A. (1976) The Literary Microcosm. Theories of interpretation of the later neoplatonists, Leiden.

CuRtius. E. R. (1998) Literatura europea y Edad Media latina, México (primera edición 1948).

De Paolis, P. (1987) "Les Saturnales de Macrobe et l'idéalisation du saeculum Praetextati“, LEC 55, S., pp. 291-30.

Flamant, J. (1968) "Le technique du banquet dans les Saturnales de Macrobe", REL 46, pp. 303- 319.

KASTER, R. (1980) "Macrobius and Servius: Verecundia and the Grammarian's Function", HSCP 84, pp. 219-62.

Marinone, N. (1946) Elio Donato, Macrobio e Servio Commentatori di Vergilio, Vercelli. 
PANCIERA, S. (1982) "Iscrizioni senatorie di Roma e dintorni 38", en Epigrafia e ordine senatorio (Atti del Colloquio internazionale AIEGL), Roma, I, pp. 658- 660.

Sluiter, I. (1998) "Metatexts and the Principle of Charity", en Schmitter, P. Y VAN DER WAL, M.J. (eds.) Metahistoriography. Theoretical and Methodological Aspects in the Historiography of Linguistics. Münster, pp. 11-27.

timpanARo, S. (2001) Virgilianisti antichi e tradizione indiretta, Firenze.

Fecha de recepción: 28-03-2014

Fecha de aceptación: 17-05-2014 